\title{
Comparison of sensitivity between real-time detection of a TaqMan assay for Batrachochytrium dendrobatidis and conventional detection
}

\author{
Stephen Garland ${ }^{1, *}$, John Wood $^{2}$, Lee F. Skerratt ${ }^{1}$ \\ ${ }^{1}$ Amphibian Disease Ecology Group, School of Public Health, Tropical Medicine and Rehabilitation Sciences, \\ James Cook University, Townsville, Queensland 4811, Australia \\ ${ }^{2}$ Pisces Molecular, 1600 Range Street, Suite 201, Boulder, Colorado 80301, USA
}

\begin{abstract}
A sensitive and quantitative TaqMan ${ }^{\circledR}$ assay for the causative agent of chytridiomycosis in amphibians (Batrachochytrium dendrobatidis) has been developed and is routinely used in diagnostic laboratories. We assessed whether the real time detection of the TaqMan ${ }^{\circledR}$ assay was as sensitive as the detection of the PCR product by agarose gel electrophoresis and ethidium bromide staining. We found, for practical purposes, that gel-based detection of the diagnostic fragment produced by means of the TaqMan ${ }^{\circledR}$ assay or by conventional PCR that used a different polymerase and reaction mix was as sensitive as the real-time detection of the TaqMan ${ }^{\circledR}$ assay. We recommend the qualified use of conventional PCR amplification combined with agarose gel electrophoresis and ethidium bromide staining for studies where only prevalence data are required, funding for equipment is limited or the acquisition of a real-time system is not cost effective.
\end{abstract}

KEY WORDS: Batrachochytrium dendrobatidis · Chytridiomycosis · TaqMan assay · Conventional PCR Resale or republication not permitted without written consent of the publisher

\section{INTRODUCTION}

Batrachochytrium dendrobatidis $(B d)$ is a major primary cause of declining frog populations (Skerratt et al. 2007) and there is an increasing global interest in diagnostic detection and monitoring of this disease organism. Boyle et al. (2004) developed a sensitive TaqMan ${ }^{\circledR}$ (Applied Biosystems) assay (TMA) for the quantitative detection of $B d$, and Hyatt et al. (2007) developed a recommended sampling and detection strategy. The assay involves the real-time detection of $B d$ from swabs run over the ventral surfaces of amphibians. Real-time PCR machines and TaqMan ${ }^{\circledR}$ assays are expensive and quantification of infection levels may not be necessary when only prevalence data are required.

However, Boyle et al. (2004), Kriger et al. (2006) and Hyatt et al. (2007) suggested that conventional PCR assays are generally less sensitive than real-time assays. Kriger et al. (2006) concluded that the conventional PCR assay for the detection of $B d$, developed by Annis et al. (2004), may lead to underestimation of prevalence compared with the TMA. This conclusion was based solely on the detection sensitivity of the conventional PCR assay as reported by Annis et al. (2004), which, among other differences, used far fewer amplification cycles (30 cycles) than the quantitative PCR (qPCR) assay developed by Boyle et al. (2004) (50 cycles). Hyatt et al. (2007) stated that real-time systems were more sensitive because they could resolve 2-fold differences in DNA concentrations compared with 10fold differences by agarose gel electrophoresis (AGE). This claim also does not prove better sensitivity for qPCR because it is the ability to detect amplification at the end of the PCR reaction that determines analytical sensitivity, not the ability to distinguish between target sequence concentrations. Goka et al. (2009) also reported reduced sensitivity between the TMA and the 
Annis et al. (2004) assay. The study by Goka et al. (2009) also does not represent a general comparison between real-time and conventional assays because the 2 assays used different primers, with potentially different amplification efficiencies, different primer concentrations and different numbers of reaction cycles. None of the data in these 3 studies precludes the possibility that a DNA sample with a low number of target sequence copies will produce sufficient amplification products using conventional PCR, with the same reaction parameters and number of cycles as the TMA assay, to be detected by AGE and ethidium bromide staining (EBS).

Bastien et al. (2008) suggested that conventional assays cannot generally be reported as being less sensitive than real-time assays unless empirical evidence is available. We therefore tested whether the TMA was any more sensitive than end-point detection of amplified products from the TMA by AGE and EBS, ensuring all factors were equal except for the detection method (real-time versus AGE and EBS). We then tested whether the TMA had greater analytical sensitivity than conventional PCR, using the same primers, a different polymerase reaction mix and AGE and EBS (now referred to as the conventional PCR assay, CPCR).

\section{MATERIALS AND METHODS}

To determine whether real-time detection of the TMA was any more sensitive than AGE and EBS, swabs ( $\mathrm{n}=101)$ taken from wild frogs Litoria spp. from North Queensland, Australia, were quantitatively analyzed for $B d$ with the TMA (Boyle et al. 2004; standard DNA extracts supplied by the Australian Animal Health Laboratory, CSIRO Australia). DNA was extracted from swabs as described by Hyatt et al. (2007). Real-time PCR analysis including reaction mix and cycling conditions followed that of Boyle et al. (2004) with the inclusion of $400 \mathrm{ng} \mathrm{hl}^{-1}$ of bovine serum albumin (BSA) to the reaction (Garland et al. 2009). Triplicate analyses were performed on a rotary analyzer (Rotor-Gene ${ }^{\mathrm{TM}} 6000$, Corbett Research) as described by Garland et al. (2009).

After real-time PCR, $12 \mu \mathrm{l}$ samples of PCR product were analyzed by AGE ( $2 \%$ gels, $5 \mathrm{~mm}$ wells) and EBS (trans-illumination at $302 \mathrm{~nm}$, Syngene Bio Imaging model GVM2530) and scored for the presence of the appropriately sized band (146 bp).

To determine whether the TMA had greater analytical sensitivity than CPCR, 3 swab extracts were arbitrarily selected that produced $B d$ levels of 1 to 2 zoospore equivalents (ZSE) per $3 \mu \mathrm{l}$ of extract $(3 \mu \mathrm{l}$ of template per $15 \mu$ reaction) and serially diluted (50\%) 7 times using a pooled sample of $B d$-negative swab extracts $(n=60)$ as the diluent. These 24 samples were analyzed in triplicate by the TMA and also with CPCR (that used another DNA polymerase and reaction mix combined with AGE and EBS) for comparison. The $20 \mu \mathrm{l}$ reaction for the cPCR analysis included $0.8 \mathrm{U}$ of FastStart Taq DNA polymerase (Roche), $0.25 \mathrm{mM}$ of each dNTP (Invitrogen 10297-018), $900 \mathrm{nM}$ of each

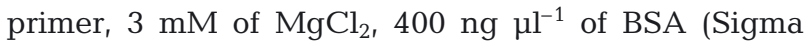
A4161) and $4 \mu \mathrm{l}$ of 1:10 diluted extract (same template to reaction volume ratio as the TMA). PCR amplification incorporated an initial denaturing step of $95^{\circ} \mathrm{C}$ for $4 \mathrm{~min}$, followed by 50 cycles of $95^{\circ} \mathrm{C}$ for $30 \mathrm{~s}, 55^{\circ} \mathrm{C}$ for $30 \mathrm{~s}$ and $72^{\circ} \mathrm{C}$ for $45 \mathrm{~s}$, and the reactions were performed in $0.2 \mathrm{ml}$ tubes in a gradient PCR machine (Mastercycler Gradient, Eppendorf).

\section{RESULTS}

The result of the triplicate-TMA analyses of 101 swabs (303 reactions) from wild frogs produced 91 negative $(30.0 \%)$ and $212(70.0 \%)$ positive reactions. Twenty-eight quadruplicate analyses of a standard $B d$ extract, representing $0.1 \mathrm{ZSE}$ per $\mathrm{PCR}$, produced an average threshold cycle $(\mathrm{Ct})$ of $33.7(\mathrm{n}=28, \mathrm{SD}=0.03$ ) (data not shown). Of the 212 positive reactions, 58 $(27.4 \%$ ) had average Ct values $>33.7$ (mean 35.6 , SD $1.28, \mathrm{ZSE}<0.1$ per reaction) (Table 1 ). Of the 58 reactions with average $\mathrm{Ct}$ values > 33.7, 56 (96.6\%) were unambiguously scored as positive by AGE. Two were ambiguous and produced very faint bands that could not be confidently scored as positive and therefore were scored as negative (data not shown). Both of these reactions produced $\mathrm{Ct}$ values $>36$ by the TMA and were still undergoing exponential amplification, producing low levels of amplified product, by the end of cycling. Low concentrations of PCR product, possibly combined with loss during loading, may have contributed to the ambiguous bands. Of the 154 that produced Ct values $\leq 33.7$ ( $\mathrm{ZSE} \geq 0.1$ per reaction) all were unambiguously scored as positive by AGE. Of the 91 negative reactions, 89 (97.8\%) were clearly negative

Table 1. Batrachochytrium dendrobatidis. The results of the triplicate analysis of 101 swabs (303 analyses), taken from wild frogs, by real-time detection of a TaqMan ${ }^{\circledR}$ assay and detection by agarose gel electrophoresis (AGE) and ethidium bromide staining (EBS). Ct: threshold cycle

\begin{tabular}{|lcc|}
\hline $\begin{array}{l}\text { TaqMan assay } \\
\text { category }\end{array}$ & Number & $\begin{array}{c}\text { Number (\%) scored the } \\
\text { same by AGE and EBS }\end{array}$ \\
\hline Negative & 91 & $89(97.8 \%)$ \\
$\mathrm{Ct}>33.7$ & 58 & $56(96.6 \%)$ \\
$\mathrm{Ct} \leq 33.7$ & 154 & $154(100 \%)$ \\
\hline
\end{tabular}



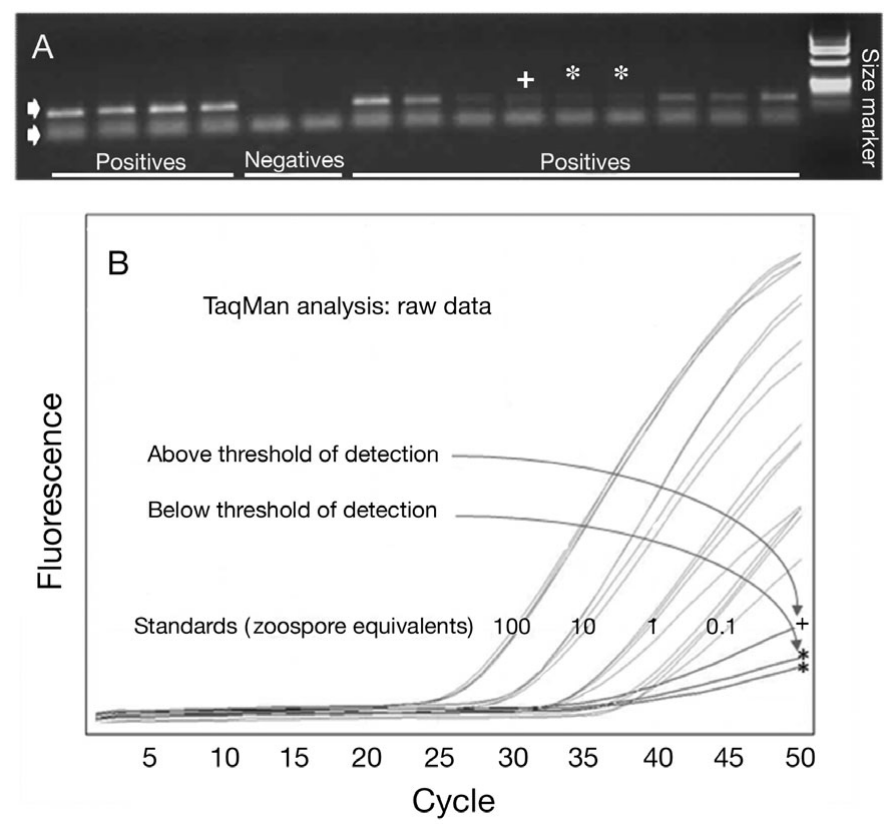

Fig. 1. Batrachochytrium dendrobatidis. (A) Agarose gel electrophoresis (AGE) and ethidium bromide staining (EBS) of 15 TaqMan analyses (5 swab extracts in triplicate). Upper arrow indicates the $146 \mathrm{bp}$ diagnostic product. Lower arrow points to primer dimer. Positive and negative reactions/lanes are grouped by the unbroken lines at the bottom of the gel. * and + combined represent the triplicate TaqMan analyses of a swab extract; 2 extracts were scored as positive by AGE and EBS but negative by the real-time detection of the amplified product $(*)$, and 1 was scored as positive by both AGE and EBS and the real-time detection of the amplified product $(+)$. Size marker is in the lane to the right. (B) Raw data output of the triplicate TaqMan analyses of a swab extract that returned 1 positive result $(+)$ and 2 negative results $(*)$. Negative reactions had increasing fluorescence after 35 cycles, but the intensity did not reach the threshold of detection by $50 \mathrm{cy}-$ cles. However, the amount of product produced was sufficient to be detected by AGE and EBS (* in A). Amplification curves for the 100,10, 1 and 0.1 zoospore equivalent standards are also included. (Note: threshold of detection cannot be indicated because it is raw un-normalized data and background levels of fluorescence vary between samples)

by AGE. Two reactions were positive by AGE but negative by the TMA (Fig. 1). The 2 negative TMA results could have been considered ambiguous because fluorescence was increasing in the latter cycles, consistent with a positive amplification, but the fluorescence did not reach the threshold of detection by the end of the assay. In addition both reactions were from the same swab extract and the third reaction of the triplicate analysis was clearly positive by both detection methods, which suggests that true positive reactions were missed by real-time detection but identified by AGE.

The results of the serially diluted extracts comparing the real-time TMA against an alternative DNA polymerase and AGE with EBS (CPCR) are presented in
Fig. 2. The numbers of ZSE per reaction for the extracts were $1.49,2.53$ and 1.02. These extracts were then serially diluted by $50 \%$ each time for 7 dilutions. The diluted extracts produced positive amplifications for both the chytrid TMA and the cPCR down to $0.05 \mathrm{ZSE}$ per reaction. The estimated concentration represents the starting concentration divided by the dilution factor. However, both procedures produced some negative results for dilutions below the concentration of $0.05 \mathrm{ZSE}$ in the reaction.

\section{DISCUSSION}

Boyle et al. (2004) found that the 0.1 ZSE standard could be reliably amplified but not the 0.01 ZSE standard. Our ability to obtain positive results for samples containing $0.01 \mathrm{ZSE}$ and the reliable amplification of samples and standard with 0.1 ZSE suggests that the analytical sensitivity of our assays were similar to that achieved by Boyle et al. (2004). The average Ct value for the 0.1 ZSE standard in our laboratory was 33.7. Of PCR products amplified using the TMA that produced Ct values $\leq 33.7$ (ZSE $\geq 0.1$ ), $100 \%$ were unambiguously scored as positive by AGE and EBS. Of extracts producing $\mathrm{Ct}$ values $>33.7,96.6 \%$ were unambiguously scored as positive by AGE. This result indicates that AGE and EBS produce a level of sensitivity that is equivalent to the TMA for practical purposes.

We also demonstrated that a similar level of analytical sensitivity could be achieved using a different assay that used the AGE and EBS detection method and different polymerase, reaction mix and PCR machine compared with that of the TMA. Both assays produced false negatives for concentrations below 0.05 ZSE in the reaction.

Detection of $B d$ based on AGE and EBS offers a sensitive alternative to the TMA. Additionally the sensitivity of cPCR assays could be increased by using higher energy $254 \mathrm{~nm}$ UV trans-illumination for the excitation of the ethidium bromide or more sensitive commercially available dyes, such as SYBR Gold (Invitrogen). New assays could also be developed and assessed for sensitivity that amplify fragments larger than $146 \mathrm{bp}$ (e.g. 300 to $500 \mathrm{bp}$ ) to increase the amount of intercalating dye bound per amplified molecule on a gel.

The use of gel-based detection does require extra care and skill when gel loading, including the need to avoid contamination of the laboratory with PCR product. A distinct advantage of the TMA is the incorporation of carry-over prevention using uracil DNA glycosylase to degrade contaminating PCR products. However, if a laboratory has the capability to perform either AGE using appropriate procedures to significantly limit 


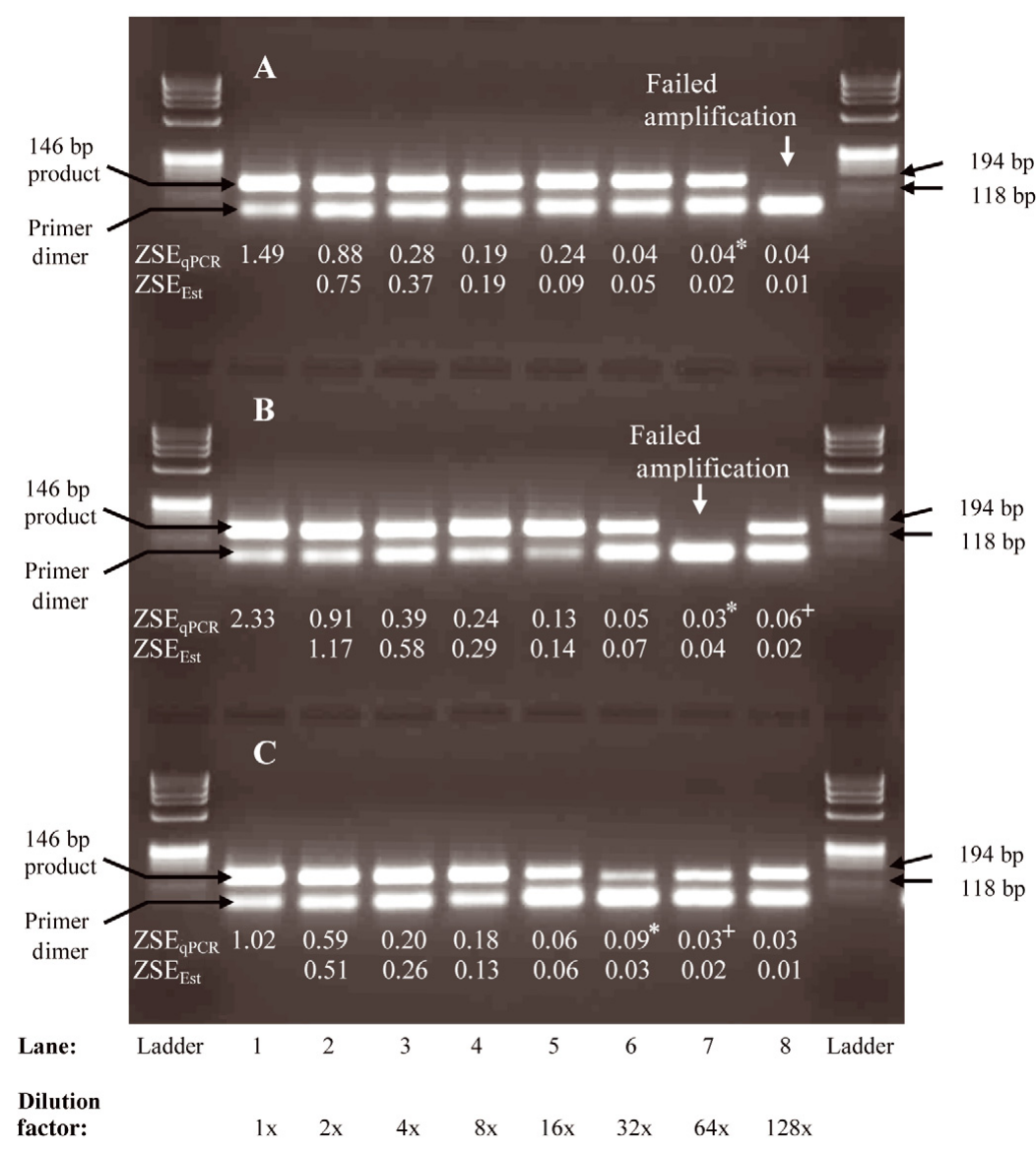

Fig. 2. Batrachochytrium dendrobatidis. Agarose gel electrophoresis and ethidium bromide staining of a $146 \mathrm{bp}$ PCR product specific for B. dendrobatidis amplified by conventional PCR from 3 different serially diluted swab extracts (A, B and C). Failed amplifications are indicated. Lane 1 represents the standard diluted extract with the further dilution factor provided under the lane number. $\mathrm{ZSE}_{\mathrm{qPCR}}$ : average zoospore equivalents as determined by the $\mathrm{TaqMan}^{\circledR}$ quantitative PCR (qPCR). qPCR was performed in triplicate and average results are generally based on 3 positive reactions $(n=3)$; however, * represents 1 failed reaction $(\mathrm{n}=2)$, and + represents 2 failed reactions ( $\mathrm{n}=1$ ). ZSE $\mathrm{ZSst}_{\mathrm{Es}}$ : estimated zoospore equivalents as calculated by multiplying the $\mathrm{ZSE}_{\mathrm{qPCR}}$ for the undiluted extract by the dilution factor

contamination or real-time analyses, then the cost differential between the conventional and real-time systems is the prime consideration. The higher capital expenditure associated with the purchase or leasing and servicing of a real-time PCR system will involve considerable outlay. To decide whether it is cost effective to obtain a real-time system, the extra expenditure to acquire the equipment and loss of returns if that capital was otherwise invested need to be less than the extra costs, including labour costs, needed to perform the CPCR and agarose gel electrophoretic analysis. It is likely that many thousands of samples would have to be analyzed per year before a real-time system is cost effective compared with cPCR analysis.
For example, the cost per reaction in the James Cook University laboratory for the TMA (master mix and probe) was in Australian dollars (AUD) 0.73 per reaction. The equivalent cost for the Taq polymerase and dNTPs for a conventional PCR reaction was also AUD 0.73 per reaction. Our cost, excluding labour, for AGE was approximately AUD 0.15 per reaction, bringing the total cost forconsumables to approximately AUD 0.88. If labour costs are included for gel loading and analysis, the cost of the conventional assay could increase by AUD 0.30 (100 analyses $h^{-1}, \$ 30 h^{-1}$ ) bringing the total cost to about AUD 1.18 per reaction. The differential cost between the conventional assay and the TMA would be about AUD 0.45 per reaction. Other costs of the assays which were considered similar, such as the rest of the labour, materials, equipment and infrastructure and management costs, are not reported here.

However, the higher capital outlay associated with the purchase or leasing of a real-time PCR system will be considerable. For example, if it costs an extra AUD 30000 to acquire a real-time PCR machine over a standard PCR machine (electrophoresis equipment would be essential in any laboratory and is not considered), there will be depreciation and servicing costs of about AUD $9000 \mathrm{yr}^{-1}$ (not considering lost investment returns). It would be necessary to process approximately $20000(20000 \times$ AUD $0.45=$ AUD 9000 $)$ reactions to make the real-time system cost effective. This is a highly conservative estimate as the cost of AGE and labour can be significantly reduced with the introduction of more efficient procedures (e.g. loading gels with multichannel pipettes). The equivalent differential cost between conventional and TaqMan ${ }^{\circledR}$ assays for $B d$ at Pisces Molecular (Colorado) is approximately USD 0.20 to 0.30 .

We therefore recommend the use of validated conventional PCR assays for studies where only prevalence data are required, funding for equipment is limited or the use of a real-time system is not cost effective. This requires that there are adequate operating procedures or methods in place to avoid carry-over contamination of PCR reactions. We also recommend that positive CPCR results for important samples are validated through DNA sequencing, given the potential relative 
loss of specificity compared with the TaqMan assay, which additionally requires the annealing of the probe for a positive result.

Acknowledgements. This study was made possible owing to funding from a tender (RFT 42/2004) entitled 'Experimental research to obtain a better understanding of the epidemiology, transmission and dispersal of amphibian chytrid fungus in Australian ecosystems' from the Australian Government Department of the Environment, Water, Heritage and the Arts and a grant (DP0452826) entitled 'Epidemiology and pathogenesis of chytridiomycosis in Australian frogs' from the Australian Research Council.

\section{LITERATURE CITED}

Annis SL, Dastoor FP, Ziel H, Daszak P, Longcore JE (2004) A DNA-based assay identifies Batrachochytrium dendrobatidis in amphibians. J Wildl Dis 40:420-428

Boyle DG, Boyle DB, Olsen V, Morgan JAT, Hyatt AD (2004) Rapid quantitative detection of chytridiomycosis (Batra-

Editorial responsibility: Stewart Johnson, Nanaimo, British Columbia, Canada chochytrium dendrobatidis) in amphibian samples using real-time Taqman PCR assay. Dis Aquat Org 60:141-148

Bastien P, Procop GW, Reischl U (2008) Quantitative real-time PCR is not more sensitive than 'conventional' PCR. J Clin Microbiol 46:1897-1900

> Garland S, Baker A, Phillott AD, Skerratt LF (2009) BSA reduces inhibition in a TaqMan ${ }^{\circledR}$ assay for the detection of Batrachochytrium dendrobatidis. Dis Aquat Org 92: 113-116

Goka K, Yokoyama J, Une Y, Toshiro K and others (2009) Amphibian chytridiomycosis in Japan: distribution, haplotypes and possible route of entry into Japan. Mol Ecol 18:4757-4774

- Hyatt AD, Boyle DG, Olsen V, Boyle DB and others (2007) Diagnostic assays and sampling protocols for the detection of Batrachochytrium dendrobatidis. Dis Aquat Org 73: 175-192

- Kriger KM, Hero JM, Ashton KJ (2006) Cost efficiency in the detection of chytridiomycosis using PCR assay. Dis Aquat Org 71:149-154

Skerratt LF, Berger L, Speare R, Cashins S, McDonald KR, Phillott AD, Hines HB, Kenyon N (2007) Spread of chytridiomycosis has caused the rapid global decline and extinction of frogs. EcoHealth 4:125-134

Submitted: August 30, 2010; Accepted: December 21, 2010 Proofs received from author(s): March 23, 2011 